\title{
Political Communications in Democratic Taiwan: The relationship between politicians and journalists Abstract
}

\author{
Gary Rawnsley $^{\mathrm{a}}$ and Qian Gong
}

\begin{abstract}
a University of Aberystwyth
b University of Leicester
\end{abstract}

\begin{abstract}
This paper assesses the present state of political communications in Taiwan through close analysis of the perceived relationship between journalists and politicians. This relationship is examined within the context of media commercialization. Based on the assumption that in cultures of democratic political communication the interaction between media and political actors involves both conflict and cooperation, we consider how journalists and politicians negotiate the balance of power between them. The empirical evidence gathered from semi-structured interviews for this paper suggests that the interaction between media and political elites in Taiwan is defined by high levels of conflict, hostility, mutual suspicion and mistrust - attributes of a relationship that can have profound implications for the legitimacy and efficacy of institutions, actors and political communications in a newly-created democratic system. The paper explains the evidence through the perspective of the 'knowledge deficit model' that operates within the context of media commercialization. This indicates that the perceptions (of the public, journalists and politicians) of the formal aspects of democracy may have been transformed, but the nuances which define the application of democratic norms (the practice of responsible journalism) remain ambiguous. More importantly, huge market pressures and the widely accepted media logic, coupled with the democratic knowledge deficit, are creating a vicious cycle in the practice of political communication in Taiwan. This perhaps provides some tentative explanation for the brisk deterioration of expectations about democracy and the media's role in it, as well as the quality of democratic political communication in Taiwan.
\end{abstract}

\section{Keywords}

Political communication, journalist, politician, new democracy, Taiwan, commercialism, knowledge deficit

\section{Introduction}

The evolution of political communication in Taiwan has occurred in parallel to the comprehensive social liberalization and political democratization that have together transformed life on the island since 1986. First the ruling party's tolerance, then recognition and finally acceptance of a legal opposition party, the Democratic Progressive Party (DPP), and the first direct competitive election for President in 1996 were all key markers in Taiwan's democratic history. The defeat of the Nationalist Kuomintang (KMT), after enjoying over fifty years of one-party rule, to the opposition DPP in the 2000 Presidential election, and the subsequent victory of the KMT in 2008 indicate that Taiwan may now be considered a consolidating democracy (O’Donnell et.al, 1986; Huntington, 1991; Diamond et.al, 1997). ${ }^{2}$

Political communications were central to the development of both a democratic culture and democratic procedures in Taiwan. The communications landscape has extended beyond any previously imagined horizon, and audiences can now choose from a multitude of outlets and platforms, demonstrating that Taiwan today enjoys a genuinely plural media environment. At the same time, Taiwan's experience of political communication indicates the island is confronting many of the same challenges that all new or juvenile democracies face. For example, Voltmer (2006: 3) has noted that the commitment to the liberal orthodoxy of media freedom within 'a marketplace of ideas' may actually amplify existing conflicts. In Taiwan's highly polarized political environment characterized by high expectations of what democracy may achieve, such challenges may be exaggerated. In this context the media and political society continue to negotiate and re-negotiate their relationship; and while politicians, journalists and audiences express disquiet about perceived media bias (Muyard, 2004), critics observe changes in media practices which indicate the growing dominance of the market: 
a noticeable decline in deference to authority prompted by claims of democratic rights to free speech, media pluralism and the rising power of commercial over state forces have encouraged the growth of tabloid-style political journalism in both print and broadcast media. News organizations now routinely resort to sensationalism to attract bigger audiences and advertising revenues, leading to concerns about finding ways to regulate lurid and invasive reporting (Rawnsley, 2004).

In this paper we assess the present state of political communications in Taiwan through close analysis of the perceived relationship between journalists and politicians. Based on the assumption that in cultures of democratic political communication the interaction between media and political actors involves both conflict and co-operation, we consider how journalists and politicians negotiate the balance of power between them. Both sets of actors are, and consider themselves to be, centers of power in their own right; both seek to influence public opinion (Lilleker, 2006; Davies, 2007; Negrine, 2008) and to project their own versions of political reality. The paper follows the assumptions which structure Paolino and Meernik's 2008 volume on Democratization in Taiwan, namely that attitudes in new democracies are important for they can support, strengthen, legitimize or weaken democratic processes and institutions. We also acknowledge that Taiwan confronts the challenge of translating normative standards of journalism into established routines of media-politics interaction. The paper frames the discussion within liberal debates about the 'watchdog' function of the media (Kelley \& Donway, 1990) and the supposed presence of a symbiotic relationship characterized by 'two sets of mutually dependent and mutually adaptive actors, pursuing divergent (though overlapping) purposes' (Gurevitch \& Blumler, 1990: 479). We ask whether in Taiwan journalists and politicians are, in Franklin's (1994: 18) words, 'accomplices in the enterprise of political communication,' adversaries in a system of political checks and balances, or whether the relationship extends beyond these normative standards and is marked by open and mutual resentment. The empirical evidence gathered for this paper suggests that the interaction between media and political elites in Taiwan is defined by high levels of conflict, hostility, mutual suspicion and mistrust - attributes of a relationship that can have profound implications for the legitimacy and efficacy of institutions, actors and political communications in a newly-created democratic system. The paper explains the evidence through the perspective of the 'knowledge deficit model' that operates within the context of media commercialization.

\section{Methodology}

This paper forms part of a larger study of political communications in new democracies conducted in eight countries representing a most similar design within geographical regions, and a most dissimilar design across regions. Each pair of countries experienced a different trajectory of political change to democracy: from Communist oligarchy (Bulgaria and Poland); from military dictatorship (Argentina and Chile); from one-party dictatorship with unfinished nation-building and ethnic fragmentation (Namibia and South Africa); and from one-party dictatorship with strong state and accelerated modernization (South Korea and Taiwan). ${ }^{3}$ Using a collaboratively-designed schedule ${ }^{4}$, the investigators conducted semi-structured interviews with three sets of actors - politicians, political journalists and 'intermediaries' (press officers, lobbyists and campaign consultants) - to determine their assessment of democracy, as well as their interaction, relationships, expectations, values and professional routines. The interview schedule was structured around four categories: orientation towards the democratic system; perceptions of their own role and of others in the study; the relationship between media and politicians; the personal characteristics and backgrounds of the respondents.

The regional study on Taiwan presented here is based on 22 interviews conducted during the 2008 Presidential election. The election provided the perfect backdrop for the fieldwork as the relationship between the media and politicians is more visible than at any other time in the political calendar, but it did cause problems for both access to interview subjects and scheduling of meetings, since both journalists and politicians were naturally pre-occupied by the election and campaign activities at this time. With the permission of the interviewees, all interviews were recorded, and the interviewees were informed that their personal details (name, position and gender) would be anonymized. The interview data were then fully transcribed and translated into English.

This paper is based on 16 interviews: nine with journalists and editors from national newspapers, magazines and television news programs; and seven interviews with politicians, 
including legislators representing the dominant parties in Taiwan. The duration of the interviews range from 37 minutes to 130 minutes, with an average of 90 minutes.

\section{Politics and Media in Taiwan}

By the time the KMT launched the liberalization and democratization of Taiwan in 1986, the state had maintained a system of strong management over print and broadcast media for over thirty years. This was justified in terms of 'national security', a handy-catch-all term that the government invoked in a climate of hostility with the People's Republic of China across the Taiwan Strait. The KMT introduced a series of laws, some deliberately vague to allow expedient application and interpretation, that delineated the responsibilities of the media and the penalties they faced if they violated any of the laws. Moreover, the registration of new titles, the number of pages a newspaper could publish, and where the newspaper could be printed and distributed were all decided by the government, meaning that from 1951 to 1987 no new licenses were issued and the number of titles in circulation was frozen at a mere thirty-one. The government also exercised control through forms of media ownership which embedded enterprises within the state structure, and a labyrinthine patron-client network that granted power and authority to manage media appointments to agencies representing the KMT, the provincial government and the state. The overlapping system of party, government and military meant that newspapers and television stations were owned by state interests, and more specifically by the KMT and KMT-related interests, ${ }^{5}$ while members of the KMT or at least those supportive of the party's political agenda were located in prominent and powerful 'gate-keeping' positions.

The restricted political environment in Taiwan under martial law, together with the clientellist structures of ownership and management, constrained the mainstream media from being little more than the mouthpiece of the government. Political communication was largely a one-way, vertical (topdown) process that transmitted government-approved news, information and propaganda, and helped economic development and 'nation-building'. Attempts to break or evade the law were met with severe punishment: during the 'white terror' (baise kongbu) of the 1950s hundreds of reporters, writers and editors were harassed, interrogated and often jailed, provoking a culture of self-censorship within media organizations (Rawnsley \& Rawnsley, November-December 2004; Rawnsley \& Rawnsley, 2001; Chao \& Myers, 1998).

When the KMT decided in 1987 to lift the laws that had restricted almost every aspect of life in Taiwan since 1949, the effect on the media was immediate and extensive. Most noticeable was the rapid proliferation in newspapers and broadcasting stations: by mid-2006, 2037 newspapers were in circulation, and the number of radio stations expanded from just 33 in 1993 to 172 in 2009 (GIO, 2010). Moreover, Taiwan now has five national television stations, including Formosa Television that reflects Taiwanese identity and issues, and a public service broadcaster, in addition to 14 digital channels and access to hundreds of cable television channels (Rawnsley \& Rawnsley, 2005). The DPP administration (200-2008) identified as a policy priority the clear separation of the media from politics: parties were required by law to surrender their shares in the media industries, thus undermining the entrenched liaison between economic interests and political power, while the complex knot of clientellist relationships was slowly untangled. This was achieved in part by revisions to the Radio and Television Act in 2003, Article 5.1 of which now states: 'Political party workers, political appointees, and elected public officials may not invest in radio-television businesses.' In other words, while political influence may not have disappeared entirely, the separation of politics and the media is codified.

Perhaps the most important aspect of the liberalization process was the KMT's explicit admission that media freedoms were not only required for the further development of Taiwan, but were a basic democratic right (Batto, 2004). However, the competition between media and the growing influence of the market and advertisers have prompted questions about the responsibility of news organizations and journalists. In 2003 Huang Hui-chen, then Director of the Government Information Office (GIO) admitted that 'Taiwan's freedom of speech is one of the most liberal in the world', but warned that 'such freedom should not be abused. The media's responsibility should be to imbue audiences with positive social values,' which is attendant to their role in democratic consolidation (Yiu, 2003). Yet all attempts to move towards regulation have met fierce resistance from journalists and news organizations who accuse the government of violating cherished and longfought for press freedom. 
It is clear from this brief summary of Taiwan's media environment prior to and following the introduction of democratic processes and institutions that the role of journalism has changed: from being the mouthpiece of government to inhabiting a sacrosanct area where self-restraint and market forces are preferable regulators than political interference. Normative values such as freedom of speech, the public interest and social responsibility remain key to understanding political communications in Taiwan and the relationship between political elites and journalists. The aim of the current study is to identify how the central actors in Taiwan's political communication system understand these core beliefs, and to understand the norms and expectations that inform their behavior and their interaction.

\section{Relationship with Each Other Democratic Change}

The first questions asked in the interviews focused on the orientation of the political system, and especially the achievement of democratization. Although the journalists and politicians interviewed for this project expressed reservations about specific features of the post-transition environment, all supported both the idea and the institutions/processes of democracy in Taiwan. This conforms to the survey data presented in the essays in Paolino \& Meernik (2008), and especially that of Wang (2008: 87-103). Wang found that citizens in Taiwan 'expressed overwhelming support for democracy as the preferred form of government even while recognizing that democracy is hardly a perfect system. ... Taiwanese commitment to democracy thus goes beyond instrumental considerations and reflects an intrinsic nature, which is a positive sign for the island's young democracy' (ibid.: 100). Moreover, when pressed to discuss how the process of political change had affected the media, politicians and journalists acknowledged that democratization had fostered the development of a media system that today enjoys more freedoms than any time in the past (although as we shall see presently, there are significant differences of opinion about the nature of those freedoms).

This unanimous support for democracy and democratization is important, for it suggests regime legitimacy and the evolution of an accepted democratic culture among Taiwan's media and political elites; it implies that Taiwan is now a consolidating democracy (Higley \& Gunther, 1992: 3; Wang, 2008: 100) that can depend on a high degree of formal support from the masses and the elites. ${ }^{6}$ In turn, democratization of the political system and liberalization within Taiwan's communications environment has transformed the media-politics interface and has impacted on the relationship between journalists and politicians. It is clear that the media have tried to adapt to democratic institutions and processes (Rawnsley \& Rawnsley, 2001; Rawnsley, 2004; Rampal, 2007), while journalists and politicians perceive a significant decline in the direct political influence over media organizations and the content of news reports:

After we consolidated democracy in Taiwan, the press earned their freedom. The press freedom not only refers to free speech, but also refers to the release of political pressure on the media. During the authoritarian period the government controlled press freedom, therefore the media self-constrained their speech. Now we have media for a democratic society, this is the first change on the positive side. (P1TAI) ${ }^{7}$.

The consequences of this acknowledgement of Taiwan's achievements in media liberalization cannot be overstated: In less than two decades Taiwan's political communications are more transparent, inclusive, and accountable than at any time in the past, and the media have emerged as influential political players in their own right. In their study of South Korea which experienced a comparable process of democratization since 1988, Heuvel and Dennis (1993: 10) described how the media there 'have been freer than ever to criticize the government, address formerly taboo issues, and expand with virtually no restraint.' Youm (1996: xiii) also noted that the press in Korea have 'evolved from a voluntary servant to an increasingly equal contender' in its relationship with political power'. In Taiwan, both politicians and journalists conceded that democratization has brought them closer to being 'equal contenders' than at any time previously, and politicians in particular have acknowledged the essential part that the media played in Taiwan's democratization. At the same time, however, the media have emerged as alternative centers of power to the political parties, a development that politicians clearly resent and which is the cause of much tension in their relationship with journalists. 


\section{Contested Freedom of Speech, Impartiality and Responsibility}

Notwithstanding the positive attitudes reflecting support for the idea and institutions of Taiwan's democracy, the interviews reveal that the political changes have created new areas of dispute between politicians and journalists. Again, this is consistent with the conclusions presented by Wang (2008: 100): ' . . . democracy in Taiwan looks better in principle than in practice as there is a substantial gap between satisfaction with democratic practice and general support for democracy'.

One such area is freedom of speech which is highly supported in principle, yet contested in practice. J1TAI for instance, claimed that:

There is ... a lack of professional understanding of freedom. ... There is nothing wrong with freedom of speech, but the condition is whether the media have sufficiently understood the concept. Unfortunately, the freedom of speech is abused.

When asked if freedom of speech should be constrained for any reason, our interviewees said:

I don't think any restriction could limit press freedom. The only limitation is prohibiting slander. We should not distinguish the freedom of press and the freedom of citizen. If the media reported false news without investigation, we should criticize the media and the judge should give a fair sentence. (P2TAI)

There are two categories of news: public and private. The protection of privacy should be a condition that restricts the freedom of speech. Unfortunately, the paparazzi of many media have infringed the right of privacy. So the right of privacy is a bottom line of freedom of speech. If it is a public issue, the freedom of speech may result in instigation ... There should be a limit on the media. (J6TAI)

These quotations suggest that freedom of speech is recognized as a major achievement in Taiwan's democratization, but that its meaning and practice are understood differently. In addition, the interviewees are concerned with the perceived lack of balance in reporting politics and evaluated press freedom with reference to the levels of media impartiality:

Taiwan has too much press freedom. For instance, one political talk show in the SET is too extreme. The consequence of this extreme political program influenced on the DPP decision makers' thoughts, it also motivated people who support the pan-green group to go further, to become extreme deep-green supporters. This talk show program misled the DPP to an extreme, and the DPP lost support of median voters. Therefore this program already affected the trend of politics in Taiwan. (P4TAI)

Thus even though the interviewees clearly believe that freedom of speech facilitates the structures and the legitimacy of democracy, they have different views on what freedom of speech entails, especially in relation to media practice. The interviewees also identified a relationship between freedom of speech and the growing dominance of market forces in a media environment which now elevates profit over public interest, and has encouraged irresponsible and sensational style journalism. ${ }^{8}$ J1TAI referred to the 'degrading of media content' and noted that freedom of speech 'has been equalized to gossip and the infringement of privacy. ... The news values have shifted from public interest to the curiosity of audiences.' Revealing the scale of this trend, J1TAI said:

News balance is no longer a value in Taiwanese media practices. This is pretty much like Fox news in the US. And as matter of fact, many Taiwanese media are using Fox News as an example.

\section{Dependents}

In the interviews, both sets of actors alluded to their mutual dependence, suggesting a symbiotic relationship. However, the politicians were more prepared to concede such a relationship than the journalists. Compare the length and depth of the following excerpts, first from the journalists: 
The relationship between journalists and politicians is mutually beneficial. Politicians need publicity while journalists rely on politicians to get information (J5TAI).

... politicians do give selected information, and sometimes even false information for political reasons. It's very rare they give full and true information. But there is a mutually dependent relationship between the politicians and journalists (J2TAI).

Contrast the brevity of their remarks with those offered by the politicians:

It is possible to influence the media but it has to be done with caution for the following reasons. Firstly, the media has its own role, it is not one's tool; one has to respect the role of the media. Secondly, the media in Taiwan have their own perspectives due to their political preferences. One also has to understand and respect their positions. Under these conditions, it is still possible to influence the media. For instance, I could tell a journalist not to report this point or help me to correct what I have said in their report. Usually journalists would cooperate on the basis of maintaining a friendly trusting relationship and not violating their principles. The reason that journalists are willing to cooperate is because it's in their best interest to keep a good relationship with me. They need my information; they don't want to cut off a good relationship. It is also due to a friendly relationship, as long as it does not violate their principles, they certainly are willing to help friends (P1TAI).

The relationship between politicians and the media is very subtle, it's like a seesaw game. Sometimes the media are using politicians for their reporting; sometimes politicians are using the media for their own means. In my case, I started to teach in ... many of my students are now in the high ranks of the media, either director or chief editor. This good network helps my influence on journalists. I can persuade them comparatively easy because of our past relationship (P2TAI).

We are the opposition party, we eagerly need help from the media. Currently the KMT does not have a direct tool of propaganda, therefore we need to rely on the media to report our positive image instead of negative ones. Therefore the media could be seen as a friend and we would like to build up a good rapport (P4TAI).

I think politicians need to have senior journalists as friends, but really good friends (P7TAI).

Ultimately, the politicians recognized the power of the media in forming their reputations, and therefore in making or breaking their political careers:

I think politicians' reputations were created by journalists, therefore very few politicians dare to offend journalists. Even though many politicians know that journalists' reports are biased or untruthful, they merely complain privately. Politicians know that there is nothing good for them if they really offend journalists (P6TAI).

Clearly the politicians were more willing than journalists to discuss the perceived symbiotic relationship between them. How might this difference be explained? In western liberal democracies political journalists do not like to admit that they are too close to the political process and are dependent on official sources for fear of losing their credibility and their reputation for objective, critical reporting. Rather, their claims to professionalism encourage them to seek out the story, verify the facts and report as objectively as possible. While journalists in democracies enjoy claiming, rightly or wrongly, an influence on the political process, they rarely acknowledge how close they are 
or have to be to their sources, preferring instead to maintain a position outside politics looking in. For politicians, on the other hand, an explicit description of their relationship with the media as mutually dependent may weaken the power of journalists and thus strengthen their own position in communicating political issues and policies with audiences.

\section{Hyper-adversarialism}

However, the interviews reveal that the symbiotic relationship between journalists and politicians in Taiwan is overshadowed by a high level of adversarialism. As observed by McNair (2009, p. 244) in established democracies, 'hyper-adversarialism' is represented by an 'aggressive, confrontational stance increasingly adopted by journalists allegedly seeking not elucidation and clarification of the pertinent facts of politics, but dramatic and crowd-pleasing contests,' and this is considered problematic for democratic politics. Some of the interviewees found this adversarial relationship disturbing; they genuinely feared that democracy is in danger unless the public trusted politicians and the politicians could trust the media, and they perceived the absence of mutual trust to indicate a systemic breakdown. ${ }^{9}$ Few were convinced that such a relationship might encourage the evolution of a healthier democratic culture with a greater degree of transparency and accountability.

Politicians were unanimously critical of current media practices and, as indicated earlier, some even questioned whether the media enjoy too much freedom. Most politicians focused on the lack of accountability:

... the media in Taiwan very often forgot their role and played a wrong role, like a political judge or legislator or prosecutor, which makes their job in relation to monitoring the government's performance a mess. Even though the media played a role as political judge, it is not a fair judge. The media have their own political positions, which results in their false charges [against] the government because they don't care about the truth' (P1TAI).

... the media are still trying to fabricate a hypocritical divinity. Both newspapers and TV news media are playing the role of god and interrogating politicians. I don't think this is wise (P5TAI).

There is clear unease among politicians about an unelected media system as an alternative center of power. Only one expressed hope that if the KMT should win the Presidential election in 2008, the media would become a 'permanent opposition party vis-à-vis the government' (P3TAI), thereby strengthening the value of an adversarial relationship.

\section{Mutual Suspicion and Contempt}

Moreover, our interviews reveal mutual suspicion, mistrust and even contempt between both groups of actors. Journalists use adjectives such as 'incompetent' and 'lazy' to describe politicians. They refer to a golden era when politicians were dedicated to public service, instead of allegedly lining their own pockets and accruing power for the sake of it. Their knowledge of political detail is described as low, and the politicians in Taiwan are considered 'unqualified' for office:

My opinions on them (politicians) are increasingly low. ... 20 years ago a responsible legislator would spend days in his working place. But now there are very few people like this in both parties. I have low opinion of them because they don't even know the issues of public interests. They have become part of the gossip (J7TAI).

... in the past eight years I was still disappointed at the way the DPP selected its staff. The party offered positions to some unqualified persons, for instance, the Minister [anonymised] who resigned only forty days after his appointment. Others were involved in corruption as soon as they were appointed. [anonymised] is no good in appointing staff. ... There are few competent officials, and the ones with administrative working experience are even fewer (J9TAI). 
Interviewee J9TAI discussed his opinions of politicians within the broader political context: 'Politics in Taiwan reflects the Taiwanese culture. We are in the early stages of democratization and therefore some of the national congressmen are not qualified.' Such contextual explanations surfaced in other interviews. P1TAI concurred with his colleagues that press partisanship ('bias') is clearly a negative aspect of Taiwan's transition, but believed that it is the expected consequence of the immaturity of democracy. For example, P3TAI noted that the 'media in Taiwan are still learning how to monitor the government':

The reason that Taiwan's media have their own positions in political reporting is because Taiwan is still a new democracy. In a mature democracy, media should have self-regulation coming from society or peer pressure, but this part is not good in Taiwan. For instance, the media in Taiwan often created false reporting, or mix news reports with comments, or report selectively because of their own political position. I think the problem of Taiwanese media is due to the above two causes: confusion of national identity and new democracy (P1TAI).

I have respect for many journalists but I don't have a high opinion of some journalists. Many journalists are too young ... they don't have time to understand some issues thoroughly. They certainly are professional journalists, but sometimes their understanding of a certain issue is not deep enough. On this occasion, their reports are biased. Surely we cannot demand too much [from] journalists because Taiwanese journalists are not well paid. Because of the low pay, our journalists are too young or inexperienced; they usually report news in a rush, therefore the quality of news is not good enough. It might take ten or twenty years for our media environment to mature (P3TAI).

Most TV journalists in Taiwan have a low salary, huge pressure, and highly competitive work, but little preparation for their news. They don't have time to study or prepare their interviews beforehand. Therefore I don't have a high opinion of journalists (P7TAI).

At the same time, of course, politicians have equally low opinions of journalists. Again the word 'unprofessional' was used by several interviewees. The media are considered not only partisan, but also corrupt, lacking the professional training and skills required to analyze the news and understand political issues, and were even accused of fabricating stories:

Most of the journalists nowadays have a close relationship with politicians; this is another reason that I look down on the journalists nowadays (P2TAI).

The media should inform the citizens of the truth. Therefore the media have the responsibility to verify their news. But most media released their news without verification (P5TAI).

Reflecting on their own behavior, some of the journalists interviewed for this project concurred with the idea that some of them do act in an unprofessional manner, though naturally this applied only to employees of rival news organizations. Bribery was a principal theme of the interviews, with journalists relating stories of colleagues who lost their professional integrity and autonomy after accepting 'gifts' from politicians.

\section{The knowledge Deficit Model and Commercialization}

How might we explain this clear mistrust between politicians and journalists in Taiwan, and is it significantly different from comparable attitudes observed in more established democracies (Brants, et.al. 2010)? In mature democracies, the relationship between journalists and politicians might be described as settled and routine, with little contest between the normative standards of political 
journalism and its practice. (Ross, 2010) The professional interaction between journalists and politicians is defined by (largely unwritten) rules and norms, allowing for a greater stability in terms of mutual expectations. (Ross, 2010, p. 279) As a new democracy, Taiwan is still negotiating and renegotiating these rules and norms, and both sets of actors are still learning how to operate and interact within a structure of democratic values. Comments that journalists are 'too young' reflect the socalled ‘juniorization' of political journalism in new democracies (Herman, 2010). Politicians and journalists in Taiwan are still learning the norms, routines and practices associated with democratic institutions and processes, especially in terms of representation, accountability and forging meaningful relationships with each other. Inadequate knowledge perhaps leads to undesirable practices in political communication that both journalists and politicians identified, and this further reflects a paradox: on the one hand, both journalists and politicians rate highly Taiwan's democracy (its ideals , processes and institutions), while their perception of each other and their work within the framework of this new democracy is decidedly negative.

\section{Media without Accountability}

Accountability is one aspect which media in Taiwan are considered to be failing, and its lack is related to insufficient knowledge of political journalism. It is clear from our interviews that though unanimously supported media freedom is thought to encourage little or no accountability. One journalist attributes irresponsible media behaviour to the deficiency in professional training:

Maybe the media liberalization has challenged the news ethics. There has been a very quick media expansion. However, the trainings on the media practitioners in terms of their ethic and professionalism are not following up. (J7TAI)

The lack of professional training for political journalists can lead to a democratic knowledge deficit because journalists lack a sensitive understanding of the criteria and principles which provide guidance on what and how to report. For example, P1TAI blames journalists who 'sacrifice some basic principles of journalism to deliver biased reporting' and J4TAI believes that good knowledge of ethics and laws will help journalists grasp what needs reporting. In addition to insufficient professional training at the personal level, unaccountable media action is also linked to a structural defect - the absence of a public service media paradigm:

Except in America, most major TV channels in Europe deliver public service. In Taiwan, there are very few TV channels with the concept of serving the public. Therefore if we have to say that the media in Taiwan should behave responsively, that is due to their choices of political interests, they presented very extreme news report to audience and left the audience with no choice but accept their report. (P7TAI)

Although they provide their own set of challenges in a commercial environment, public service media still offer valuable experiences in sustaining vital political communication in many established democratic countries. More importantly, the norms of public service media such as objectivity, the search for 'truth', accuracy, a commitment to investigation, impartiality, and the representation of minority interests all overlap with many principles of political journalism. These norms also sit uncomfortably alongside the unaccountable actions of Taiwanese media - bias, aggression, superficiality, fabrication and partisanship. Therefore it is possible to hypothesize that insufficient professional training and weak public service media in Taiwan can lead to a deficit in communicating politics in a trustworthy, objective and accountable way. In fact this insufficiency significantly undermines the outcomes of the journalists in monitoring the government and informing the public, and both sets of actors believe that Taiwanese now perceive journalists as one of the least trustworthy groups in society (J8TAI).

\section{Political Interference and Bribes}

The deficit of democratic knowledge of both journalists and politicians is also reflected in their shaky relationship, which resonates with the perception of incompetence and contempt that they have of each other. Since the lifting of martial law, political intervention in news freedoms decreased sharply. 
However, although crude methods of interference such as prosecution, arrest, and demotion are no longer very prominent, legacies of political control are still noticeable. The close relationship inherited from the period before democratization between KMT politicians and journalists undermines media autonomy and their subsequent watchdog role. Politicians openly admit that they could focus public attention on a special issue by dictating to the media:

I would coach the journalist from the United Daily how to analyze a specific event, then this journalist would report all my opinions in relation to that event. (P2TAI)

Meanwhile journalists benefit from a close relationship with politicians because of the media's need for access to news sources inside the political system. If the journalist does not conform, then 'this journalist would be denied information as well as benefits such as chances to travel abroad'. (J9TAI)

The KMT did quite a lot to get media support. Some journalists were offered opportunities to go abroad every year ... They were given bonuses and public relation fees to cover their expenses abroad. (J5TAI)

In established democratic countries journalists and politicians tend to keep each other at arm's length with the assumption that only autonomous media can effectively supervise political power. In very rare cases politicians can dictate content to the media without disguising it as 'media relations' through spin doctors. The political intervention of media content in Taiwan stands in sharp contrast to the democratic norms of media autonomy and independence. The prevailing culture of intervention, a legacy of authoritarianism, disrupts the routines and expectations of journalists and politicians in a democratic setting. Uncertainties here further cloud the construction and consolidation of democratic values of key players in political communication.

\section{Commercialization}

Connected to the concept of knowledge deficit is the highly-competitive market model. The media environment in Taiwan is defined by saturation, as 64 cable television operators, seven 24hours news channels and 2037 registered newspapers compete for audiences among a population of just 23 million (The Republic of China Yearbook, 2009). Between 2008 and 2009, advertising revenue in the cable and satellite industry fell 5.8 percent as Taiwan's economy slowed. (Bloomberg, 2009) Against such a backdrop, the competition between media intensifies and helps explain the growth in tabloid-style political journalism. This is consistent with experience elsewhere: For example Ross (2010: 288) demonstrates that in New Zealand, also characterized by a small population served by a large number of media, 'trivial political actions are subject to endless scrutiny.'

Several interviewees believed there is a clear correlation between the number of media and the decline in responsible reporting. P5TAI's solution to this dilemma was quite drastic: 'If we could reduce some channels, for instance from fifty to two, probably it would improve the quality of their reports.' The journalists agreed with this assessment of the problem, suggesting that the proliferation of news outlets was a major cause of public mistrust in the media: 'The more media we have, the poorer the quality of the journalists. This is a vicious circle - media need more journalists, so everyone can become a journalist. ... Therefore the general quality of the journalists is getting worse' (J8TAI):

The media have provided much more information than the public needs. This is because of the high level of competition between the media. It is hard to imagine that there are so many 24-hours news channels in Taiwan which is only a small island. There is an over-supply of political discussion programs, which has led to a decline in the quality of political news. They have guided the public's attention to insignificant issues such as political conflict and political gossip.... The lack of information on the public interest is related to the commercialized operation of the Taiwanese media (J7TAI). 
We used to work very hard, for example doing background research on interviewees...but nobody does this now. There are so many media. Journalists don't necessarily need to ask 'good' questions, because there is no time. (J1TAI)

These quotations reflect the introspective approach of journalists in Taiwan to their own profession. They observed the absence of self-regulation, and confessed they were usually unwilling to admit mistakes; that they do sometimes report the news without concrete evidence or accurate sources; they focus far too much on negative news; and they do not investigate the causes and possible solutions of problems. Politicians, on the other hand, were more critical of their 'natural adversaries', remarking that journalists do not simply report politics, but comment and make ill-informed judgments. The politicians claimed that such behavior is detrimental to the democratic process, and reflected how the unelected and unaccountable media enjoy too much freedom.

These observations by politicians can be related to such structural problems as the overly competitive media environment. The interviews alluded to the pressure on journalists to produce more news in a very short time which means less time to research and understand a story's context. Market pressures further contribute to the knowledge deficit among journalists and politicians in Taiwan where media logic - 'a strategy that the media use to maintain their relationship with a mass audience on which they depend for their economic survival' (Voltmer, 2006: 8) - is widely accepted. In such an interactive system of political communication dramatization, sensationalism and gossip help define audience tastes. Since media logic infers that in a commercial system audience demand determines what the media produce, the interaction between journalists and the public creates a vicious circle in which the popular thirst for sensationalism influences the output of journalists. This in turn contributes to what we may understand as their underdeveloped democratic knowledge and their perceived deficiency of political journalism skill-sets: the research presented here suggests that an over-developed market place in a new democracy de-emphasizes the professional values of impartial, accurate and objective investigation.

\section{Conclusions}

This paper has hypothesized that it is possible to assess the condition of Taiwan's political communications by discussing with journalists and politicians about how they see themselves, and each other and their relationship. In this way, we not only acquire a snapshot of the interface between politics and the media in the democratic era, but we can also make assumptions about substantial issues like political culture and legitimacy, both of which rest as much upon perception, tolerance and acceptance as upon the design and efficacy of institutions and processes.

\section{Symbiotic and Hostile Relationship}

The information collected confirms the conceptualization of political communication described by Blumler and Gurevitch (1990: 479) as a system that entails the interactions of 'two sets of mutually dependent and mutually adaptive actors, pursuing divergent, though overlapping purposes'. It is clear that journalists and politicians in Taiwan do enjoy the same kind of symbiotic relationship as their peers throughout the democratic world, with journalists needing the politicians for information and access to the political system, and politicians depending on the journalists for wider exposure of themselves and their policies. This relationship is underpinned by the democratic changes that have occurred in Taiwan that enable transparent political communication.

Yet the interviews also suggest that the relationship reflects the problems associated with political communications in new democracies, and that journalists and politicians are still negotiating their roles, responsibilities and interactions. Moreover, both sets of actors remain uncertain about the norms and routines of their professional relationship, creating rudimentary perceptions of themselves and each other. While there is evidence of mutual dependence, there are also indications of reciprocal suspicion, mistrust and even contempt which go beyond the experience of mature democracies where the codes of interaction are more routine (Ross, 2010). The media gained their power to criticize the government after martial law was lifted; however, sensationalism, bias, fabrication and manipulation all provoking causing mutual suspicion, mistrust and contempt between journalists and politicians constrains the role of the media as watchdogs and facilitators of a healthy and democratic system of political communications. This again suggests that becoming a real mature democracy requires more than supporting the surface values of democracy such as media checks and balances. Rather, 
democratic maturity involves the constant review of the nuances of the political-media relationship and an appraisal of how these democratic values might be applied.

\section{Knowledge Deficit and Commercialization}

The interviews reveal that both sets of actors expect each other to play a responsible role in democratic Taiwan. When asked to describe their work, the interviewees used the kind of normative language of duties and expectations associated with liberal approaches to political communication: journalists 'should' be critical; they 'should criticize and watch over various issues'; they should 'safeguard justice and monitor the power-holders'; 'criticizing government is the media's natural duty.' However, definitions of 'responsible', 'critical' and 'freedom of speech' varied not only between, but also among journalists and politicians, and this is the main area of conflict between the two sets of actors. Most politicians believed that journalists are too critical or are critical for the wrong reasons; therefore the media are not fulfilling their democratic responsibility as watchdog on politicians for the benefit of democracy or their audiences (citizens), but for media proprietors and political interests. This indicates that the perceptions (of the public, journalists and politicians) of the formal aspects of democracy (for example, the role of the media as an instrument of accountability and transparency) may have been transformed, but the nuances which define the application of democratic norms (the practice of responsible journalism) remain ambiguous. The low level of knowledge of basic concepts in democratic political communications, such as accountability and autonomy, together with the growth in unprofessionalism and 'incompetence', suggest the political communication process suffers from a knowledge deficit, consistent with the 'juniorization' found in other new democracies (Wasserman, 2010). Moreover, the mutual mistrust between politicians and journalists is partly caused by the highly commercial framework within which Taiwan's media operate. As research in other new democracies has discovered, commercialism and intense media competition appear to encourage the tabloid-style political journalism that is so prevalent in modern Taiwan. More importantly, market pressures together with the widely accepted media logic and the democratic knowledge deficit, are creating a vicious cycle in the practice of political communication. This perhaps provides a tentative explanation for the brisk deterioration of expectations as well as in the quality of democratic political communication in Taiwan in its 20 years life as a democracy. The brisk deterioration in the relationship between politicians and journalists to a point that is beyond that expected or found in more mature democracies suggests something different about this particular case-study. Taiwan is still a young democracy and remains an adolescent in a hurry to grow up, but one that does not yet fully understand the implications and consequences of democracy on the mediapolitics interface. It is possible to argue that the pace of Taiwan's transformation has resulted in the underdevelopment of norms and routines that might govern the relationship between politicians and journalists, and which moderate the tensions that surface in their interaction.

\section{Notes}

1. The result of the 2008 election conforms to Huntington's (1991: 266-7) 'two-turnover test' that characterizes a consolidating democracy.

2. The research was funded by the British Academy, Ref LRG-45511. Further information can be found at http://polcomdem.wordpress.com/

3. The collaboration allowed for minor flexibility according to the political and cultural context of the specific countries investigated.

4. With the exception of a few Taiwanese-language independent newspapers controlled by the Taiwanese and located in the south of the island, such as the Independent Evening Post (zi wanbao), People's Daily (minzhong ribao) and Taiwan Times (Taiwan shibao). In addition there was a thriving underground illegal media. (See Jacobs, 1976; and Rawnsley, 2000).

5. Wang (2008) found that the strength of mass support for democracy is conditional on government performance, and can weaken during periods of political or economic crisis.

6. All interviewees are anonymized by using sample code following a standard: Subsample running number - country code. Therefore 'P1TAI; indicates Politician - No.1 - Taiwan. Journalists are coded similarly, for example, J4TAI indicates Journalist - No.5 - Taiwan.

7. Politicians throughout the developed world have criticized the media's tendency to 'dumbdown' their political coverage, and research has identified a correlation between trivialization and 
public antipathy towards politics. See Franklin, 1994; Straw, 1999; Sparks, 2000; Ross, 2002; Gill, et.al., 2005.

8. Survey data indicates that voters in Taiwan trust the Legislative Yuan, Taiwan's legislature, least of all institutions involved in the political process. Trust in the media is placed just above the Legislative Yuan. Elites trust the media least of all. Both the public and the elites trust the military most. See Tsai, Chen \& Yu, (2008:81).

\section{References}

Batto, P. (2004). The consequences of democratization on Taiwan's daily press. China Perspectives, $51,64-79$.

Brants, K., de Vreese, C., Moller, J. \& van Praag, P. (2010). The real spiral of cynicism? Symbiosis and mistrust between politicians and journalists. The International Journal of Press/Politics, $15,25-40$.

Bloomberg (2009, March 5). Next media plans to launch two TV stations next year. Taipei Times Online Retrieved from http://www.taipeitimes.com/News/biz/archives/2009/03/05/2003437652

Chao, L., \& Myers, R.H. (1998). The first Chinese democracy: political life in the Republic of China on Taiwan. Baltimore: Johns Hopkins University Press.

Davies, A. (2007). The mediation of power: a critical introduction. London: Routledge.

Diamond, L., Plattner, M.F., Chu, Y.H., \& Tien, H.M. (1997). Consolidating the third wave democracies: regional challenges. Baltimore: Johns Hopkins University Press

Franklin, B. (1994). Packaging politics. London: Arnold.

Gill, M., Healey, J., \& McHugh, D. (2005), MPs and politics in our time. London: Dod's Parliamentary Communication.

Gurevitch, M., \& Blumler, J. (1990). Political communication systems and democratic values. In J. Lichtenberg (Ed.), Democracy and the mass media (pp. 269-289). Cambridge: Cambridge University Press.

Hallin, D. (1992). The uncensored war. Berkeley: University of California Press.

Heuvel, J.V., \& Dennis, E.E. (1993). The unfolding lotus: East Asia's changing media. New York: Columbia University.

Higley, J., \& Gunther, R. (1992). Elites and democratic consolidation in Latin America and Eastern Europe. Cambridge: Cambridge University Press.

Huntington, S. (1991). The third wave: democratisation in the late twentieth century. Norman: University of Oklahoma Press.

Jacobs, B.J. (1976). Taiwan's press: political communications link and research resource. China Quarterly, 68, 778-788.

Kelley, D., \& Donway, R. (1990). Liberalism and free speech, in J. Lichtenberg (Ed.), Democracy and the Mass Media (pp. 66-101). Cambridge: Cambridge University Press.

Lilleker, D. (2006). Key concepts in political communication. Thousand Oaks, CA: Sage.

McNir, B. (2009). Journalism and democracy. In K. Wahl-Jorgensen \& T. Hanitzsch (Eds). The handbook of journalism studies (pp. 237-249). London and New York: Routledge.

Moorcroft, P.L., \& Taylor, P.M. (2008). Shooting the messenger. Washington DC: Potomac Books.

Muyard, F. (2004). Taiwan, the birth of a nation? China Perspectives, 53, 33-48.

Negrine, R. (2008). The transformation of political communication: continuities and changes in media and politics. Basingstoke: Palgrave Macmillan.

O’Donnell, G., Schmitter, P.C., \& Whitehead, L. (1986). Transitions from authoritarian rule (Vol. 14). Baltimore: Johns Hopkins University Press.

Paolino, P., \& Meernik, J. (2008). Democratization in Taiwan: challenges in transformation. Aldershot: Ashgate.

Rampal, R. (2007). First democracy in Chinese history: media's role in the democratization of Taiwan. In I.A. Blankson \& P.D. Murphy (Eds.), Negotiating democracy: media transformations in emerging democracies (pp. 99-122). New York: State University of New York Press.

Rawnsley, G. D. (2004). Treading a fine line: democracy and the media in Taiwan. Parliamentary Affairs, 57, 209-222. 
Rawnsley, G.D., \& Rawnsley, M.Y.T. (2001). Critical security, democratisation and television in Taiwan. London: Ashgate.

Rawnsley, G.D., \& Rawnsley, M.Y.T. (2004). Media reform since 1987. China Perspectives, 56, 4655.

Rawnsley, G.D., \& Rawnsley, M.Y.T. (2005). Public television and popular empowerment in Taiwan. Public Affairs, 78, 15-30.

Rawnsley, G.D. (2000). The media and popular protest in Taiwan. Historical Journal of Film, Radio and Television, 20, 565-580.

Ross, K. (2002). Women, politics, media: uneasy relations in comparative perspective. Cresskill, NJ: Hampton Press.

Ross, K. (2010). Danse macabre: politicians, journalists and the complicated rumba of relationships. The International Journal of Press/Politics, 15, 272-294.

Schudson, M. (2008). Why democracies need and unlovable press. London: Polity.

Sparks, C. (2000). Introduction: the panic over tabloid news. In C. Sparks \& J. Tulloch (Eds.), Tabloid tales: global debates over media standards. New York: Rowman \& Littlefield.

Straw, J. (1999). Wanted: one bold editor. British Journalism Review, 10, 29-34.

The Government Information Office of Taiwan (2009). The Republic of China yearbook. Chapter 2 people and language. Retrieved from http://www.gio.gov.tw/taiwan-website/5gp/yearbook/ch02.html

The Government Information Office of Taiwan (2009). The Republic of China yearbook. Chapter 19 mass media. Retrieved from http://www.gio.gov.tw/taiwan-website/5-gp/yearbook/ch16.html

Tsai, C.H., Chen, L.H., \& Yu, C.H. (2008). Comparing consensus on Taiwan democracy among the mass public and elites. In P. Paolino \& J. Meernik (Eds.), Democratization in Taiwan: challenges in transformation (pp.71-86). Aldershot: Ashgate.

Voltmer, K. (2006). The mass media and the dynamics of political communication in processes of democratization. In K. Voltmer (Ed.), Mass media and political communication in new democracies (pp.1-20). London: Routledge.

Wang, T.Y. (2008). Democratic commitment in Taiwan: an analysis of survey data. In P. Paolino \& J. Meernik (Eds.), Democratization in Taiwan: challenges in transformation (pp.87-103). Aldershot: Ashgate.

Wasserman, H. (2010) Freedom's just another word? Perspectives on the media freedom and responsibility in South Africa and Namibia. Manuscript submitted for publication

Yiu, C. (2003, October 12). New group takes aim at “vulgar” TV. Taipei Times Online. Retrieved from http://www.taipeitimes.com/News/front/archives/2003/10/12/2003071352

\section{Acknowledgement}

The authors would like to thank Professor Jay Blumler for his comments and suggestions on an earlier draft of this paper.

\section{Appendix: Interview schedule}

Journalists

J1TAI: China Times, interviewed 19 March 2008; 28 March 2008

J2TAI: FTV News Department, interviewed 28 March 2008

J3TAI: Next Magazine, interviewed 19 March 2008

J4TAI: CTS News Department, interviewed 25 March 2008

J5TAI: TVBS News Department, interviewed 26 March 2008

J6TAI: Manager, CTI, interviewed 21 March 2008

J7TAI: CTI Satellite station, interviewed 26 March 2008

J8TAI: E-news, BCC, interviewed 26 March 2008

J9TAI: Ex-China Times, United Daily News, CTS and Super TV, interviewed 27 March 2008

Politicians

P1TAI: DPP, interviewed 27 March 2008

P2TAI: KMT, interviewed 26 March 2008

P3TAI: KMT, interviewed 27 March 2008 
P4TAI: KMT, interviewed 1 April 2008

P5TAI: KMT, interviewed 25 March 2008

P6TAI: NGO, interviewed 1 April 2008

P7TAI: DPP, interviewed 1 April 2008 